\title{
Measurement of snow-hardness distribution
}

\author{
Yukari Takeughi, ${ }^{1}$ Yasuaki Nohgughi, ${ }^{2}$ Katsuhisa Kawashima, ${ }^{3}$ Kaoru Izumi ${ }^{4}$ \\ ${ }^{1}$ Nagaoka Institute of Snow and Ice Studies, NIED, Suyoshi, Nagaoka 940, Japan \\ ${ }^{2}$ National Research Institute for Earth Science and Disaster Prevention, 3-1 Tennodai, Tsukuba, Ibaraki 305, Japan \\ ${ }^{3}$ Shiozawa Snow Testing Station, Railway Technical Research Institute, Gonoda, Shiozawa, Niigata 949-64, Japan \\ ${ }^{4}$ Research Institute for Hazards in Snowy Areas, Niigata University, Niigata 950-21, Japan
}

\begin{abstract}
Distributions of snow hardness minutely measured with a handy-type digital load-gauge (push-pull gauge) are demonstrated. This push-pull gauge is of compact design and is useful for precise measurement of tension and compression loads. It can measure the maximum strength of a snowpack when it is destroyed by the attachment pushed horizontally into the side of the pit. Because it takes only a few seconds for one measurement, snow-hardness distribution can be measured at very small space intervals more quickly and with less effort than by using any previous hardness meter, such as a rammsonde, Canadian gauge, Kinosita-type hardness meter, and so on.

Snow-pit observations were made at Saiho, Sapporo and Minakami, Japan, in the winter seasons of 1996 and 1997. The snow hardness was measured with the push-pull gauge at regular intervals of $5 \mathrm{~cm}$ vertically and $10 \mathrm{~cm}$ horizontally. Some weak layers between harder layers could be detected with the push-pull gauge whereas they could not be using the rammsonde. The hardness of snow was observed to be almost uniform horizontally before snowmelt. Once meltwater infiltrated into the snowpack, its distribution became heterogeneous. It was revealed that the hardness of the fine-grained compacted snow layer with grain-sizes less than $0.5 \mathrm{~mm}$ showed a high correlation with the fourth power of the snow density.
\end{abstract}

\section{INTRODUCTION}

The hardness of snow, which is one of the basic physical properties of snow, is expressed as the resistance force of snow when a rigid body is pushed into the snowpack. Previous hardness meters used for field observations, such as the rammsonde, Canadian gauge and Kinosita-type hardness meter (Kinosita, 1960), are well known. The push-pull gauge used in this study is a handy-type digital load-gauge (Fig. 1). It can measure the maximum strength of snowpack even when it has been destroyed by pushing the attachment horizontally into the snow-pit wall, and the measured force value is automatically expressed on the display. Because it

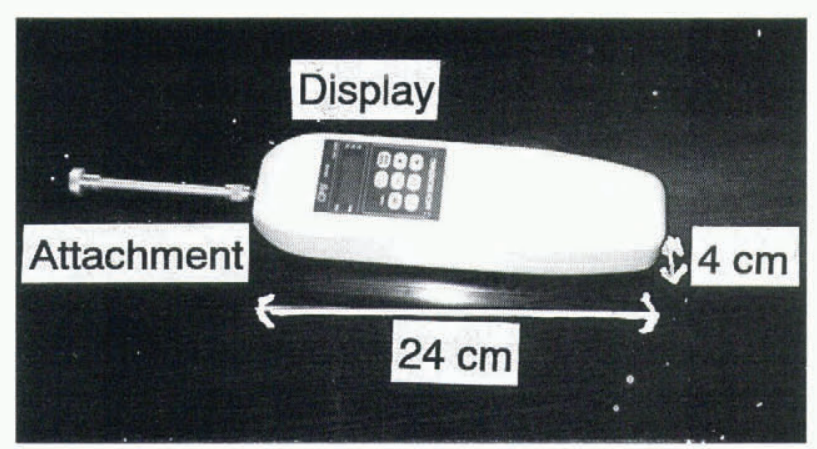

Fig. 1.The push-pull gauge used in this study. The diameter of the attachment is $14 \mathrm{~mm}$. takes only a few seconds for one measurement, anyone can measure the snow-hardness distribution at very small intervals more quickly and with less effort than by using any earlier hardness meter.

\section{OBSERVATION METHOD}

Snow-pit observations were carried at Saiho in Nakazato village, Niigata prefecture, on 27 February 1996 and in Sapporo, Hokkaido, on 20 March 1996. The snow depth was $285 \mathrm{~cm}$ at Saiho and $90 \mathrm{~cm}$ at Sapporo. Snow hardness was measured with the push-pull gauge at regular intervals of $5 \mathrm{~cm}$ vertically and $10 \mathrm{~cm}$ horizontally at both observation sites. In addition, measurements of stratigraphy, snow temperature, snow density, liquid-water content and grain-size were made. To compare the push-pull gauge with other hardness meters, the snow hardness was also measured with a rammsonde at Saiho. In order to determine the relationship between snow hardness measured with the push-pull gauge and snow density, a snow-pit observation was carried out at Minakami, Gunma prefecture, on 26 February 1997. Snow hardness was measured twice close to the point where the density had been measured. Snow temperature was also measured at the same point. The measured value expressed on the display of the push pull gauge is given in Newtons $(\mathrm{N})$, and then it is divided by the cross-sectional area $\left(15.4 \times 10^{-5} \mathrm{~m}^{2}\right)$ of the attachment to convert resistance stress to Pa units. 


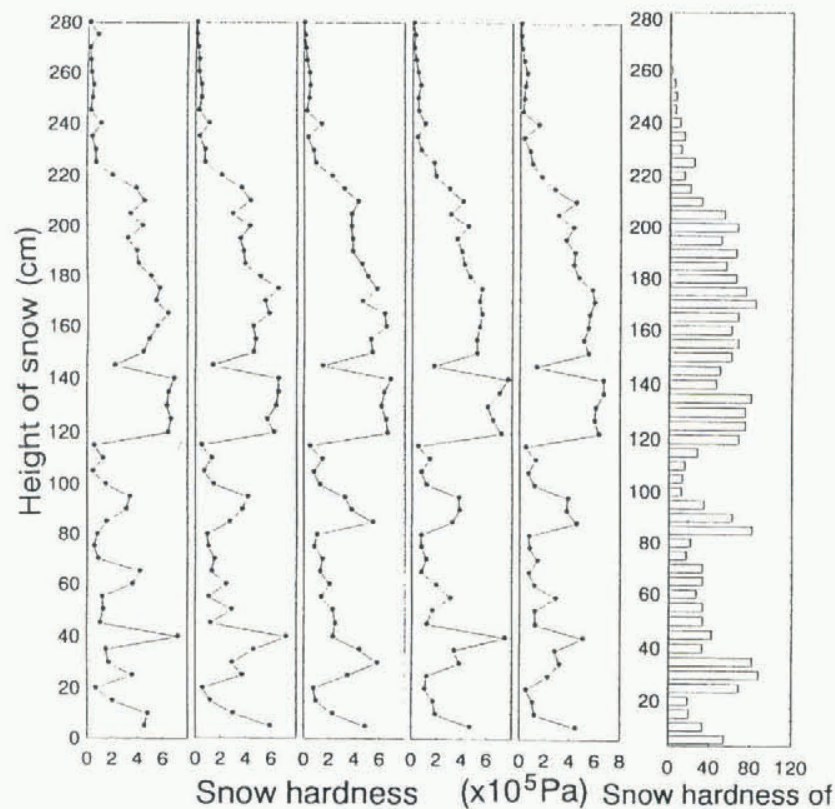

Rammsonde $(\mathrm{kg})$

Fig. 2. Snow-hardness profiles measured with the push-pull gauge and the rammsonde.

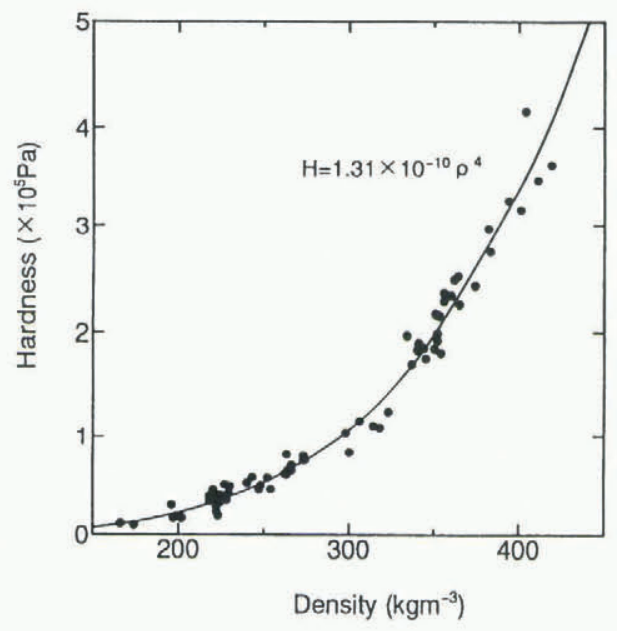

Fig. 3. Relationship between snow hardness and snow density for fine-grained compacted snow.

\section{RESULTS AND DISGUSSIONS}

Comparison between the push-pull gauge and the rammsonde

Snow-hardness profiles measured with the push-pull gauge and a rammsonde at Saiho are shown in Figure 2. Five profiles at $10 \mathrm{~cm}$ intervals were obtained with the push-pull gauge. Although the hardness profiles show very similar variations in hardness, weak layers, found at heights of 145 and $115 \mathrm{~cm}$ in the profiles measured with the push-pull gauge, could not be detected clearly by the rammsonde. It is difficult for the rammsonde to detect a weak layer between hard layers because it measures the integrated values of snow hardness. On the other hand, the push-pull gauge can measure snow hardness at small space intervals, so that it is very useful for detecting weak layers which may cause avalanches.

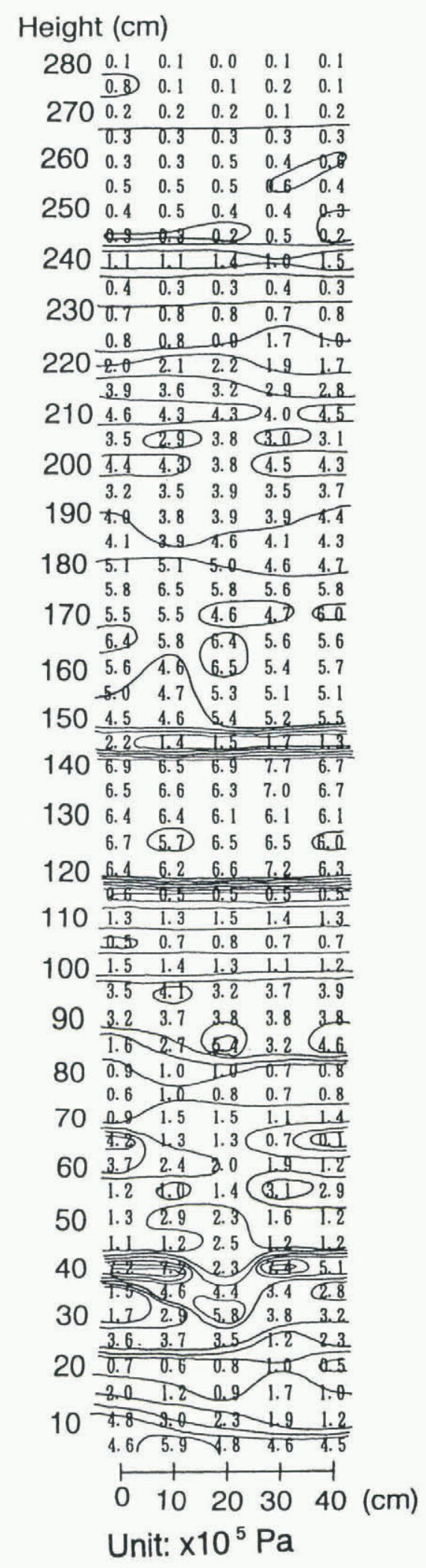

Fig. 4. The spatial distribution of snow hardness at Saiho before the melt season, 27 February 1996.

\section{Relationship between snow hardness and density}

The relationship between snow hardness and density obtained at Minakami is shown in Figure 3. The mean value of two measurements was adopted as the value of the snow hardness of fine-grained compacted snow layers in which grain-sizes were less than $0.5 \mathrm{~mm}$. Although the snow hardness depends not only on the density but also on the snow structure and temperature, the measured result shows that the hardness of the compacted snow layer with a small 

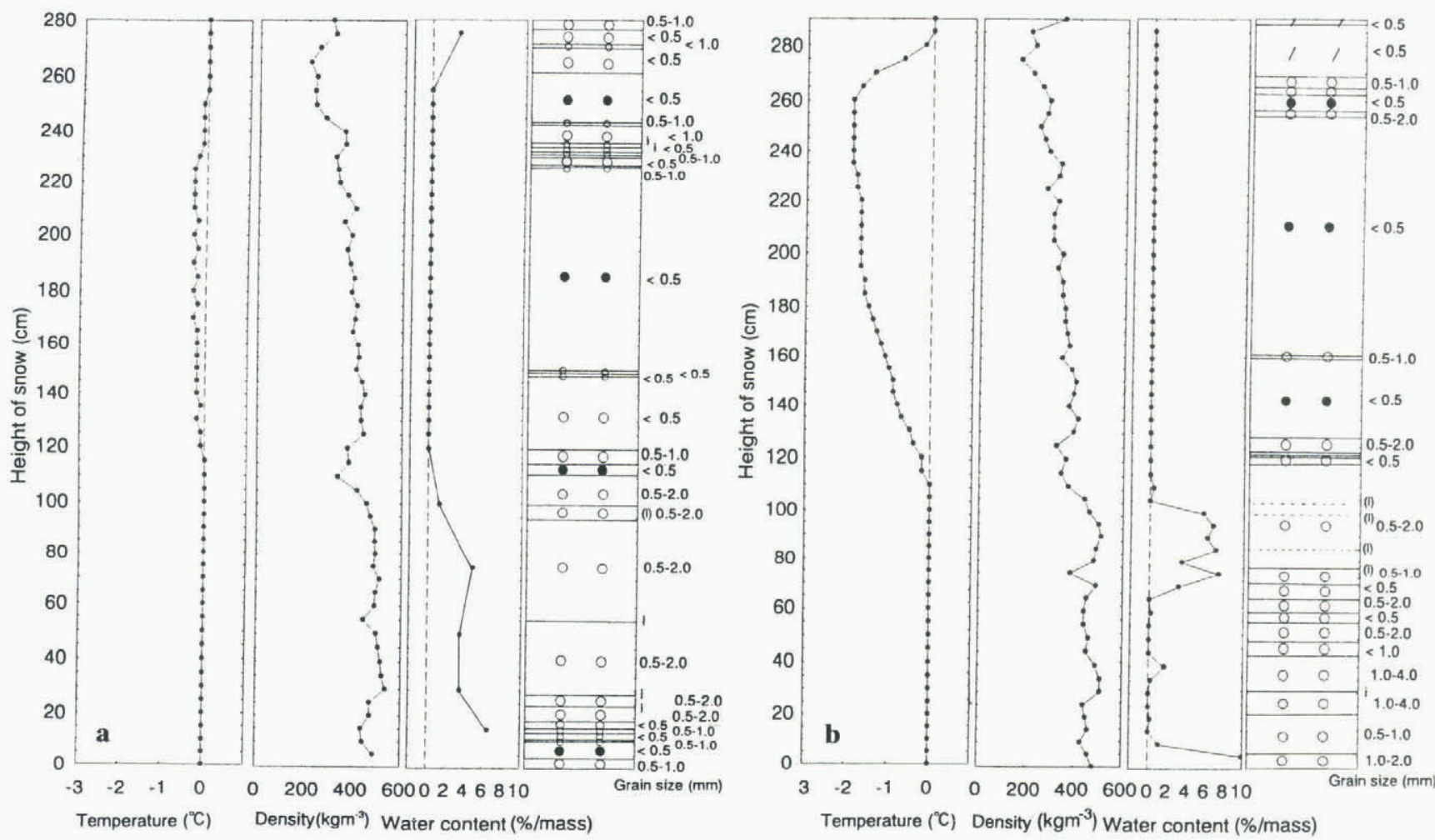

Fig. 5. (a) The results of the snow-pit observation at Saiho on 27 February 1996. ( $b$ ) The results of the snow-pit observation at Saiho on 13 February 1996. The classification for snow is according to Colbeck and others (1990).

grain-size (less than $0.5 \mathrm{~mm}$ ) reflected the density very well and it did not depend on snow temperature which ranged from about $-3^{\circ}$ to $0^{\circ} \mathrm{C}$. The relationship between hardness and density can be given as follows:

$$
H=1.3 \times 10^{-10} \rho^{4}
$$

where $H$ is hardness $(\mathrm{Pa})$ and $\rho$ is snow density $\left(\mathrm{kg} \mathrm{m}^{-3}\right)$. The correlation coefficient (0.98) was very high. Kinosita (1960) has also pointed out that the hardness is proportional to the fourth power of the density.

\section{Snow-hardness distribution before the melt season}

Snow-hardness distribution measured at Saiho is shown in Figure 4 . The hardness was smallest near the surface and
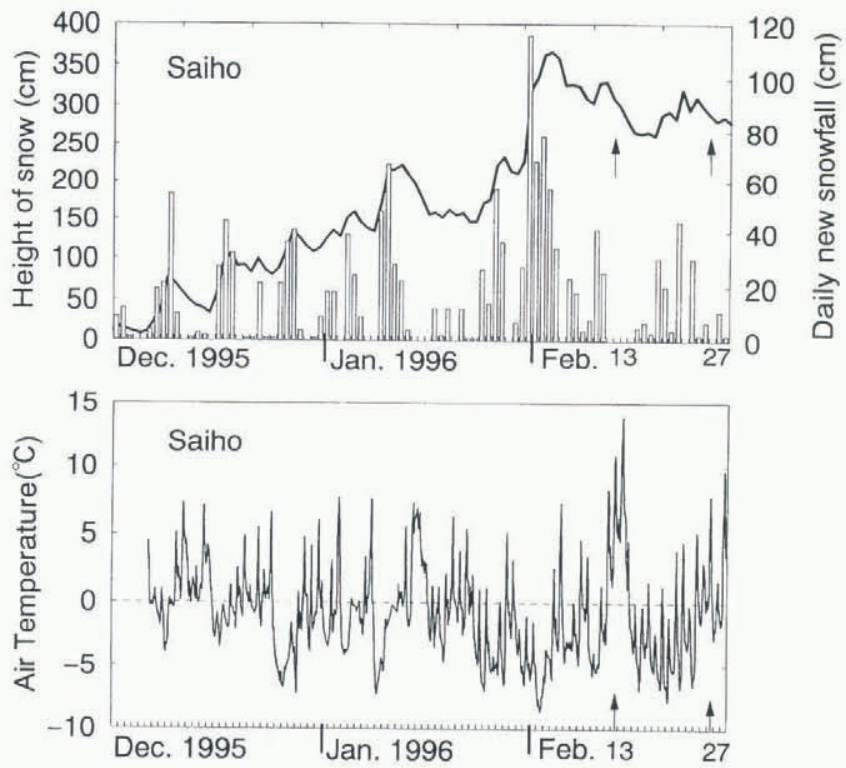

Fig. 6. Changes of snow depth, daily new snowfall and air temperature at Saiho from December 1995 to February 1996. increased with depth. The largest value was found around a depth of $120 \mathrm{~cm}$. Just above and below this hardest layer, the weak layers mentioned above can be seen. Above a height of about $120 \mathrm{~cm}$ above the ground, the contour lines are stratified and almost parallel to the snow surface, while they are not parallel and are very complicated below a height of about $110 \mathrm{~cm}$. The reason for this difference will be discussed in Figures 5 and 6.

The results of snow-pit observations are shown in Figure 5. On 27 February, the granular snow was isothermal $\left(0^{\circ} \mathrm{C}\right)$ between 0 and $110 \mathrm{~cm}$ and the fine-grained compacted snow was below $0^{\circ} \mathrm{C}$ above a height of $120 \mathrm{~cm}$ (Fig. 5a). On 13 February, the fine-grained compacted snow layer could be distinguished clearly from the granular layer (Fig. 5b). The density of the compacted snow layer varied between 200 and $400 \mathrm{~kg} \mathrm{~m}^{-3}$ whereas it was about $500 \mathrm{~kg} \mathrm{~m}^{-3}$ in the granular-snow layer.

Changes in snow depth, daily new snowfall and air temperature at Saiho from December 1995 to February

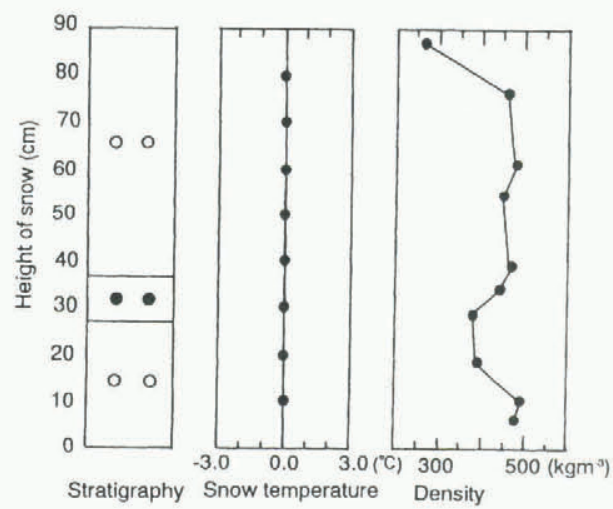

Fig. 7. The results of the snow-pit observation at Sapporo on 20 March 1996. The classification for snow is according to Colbeck and others (1990). 


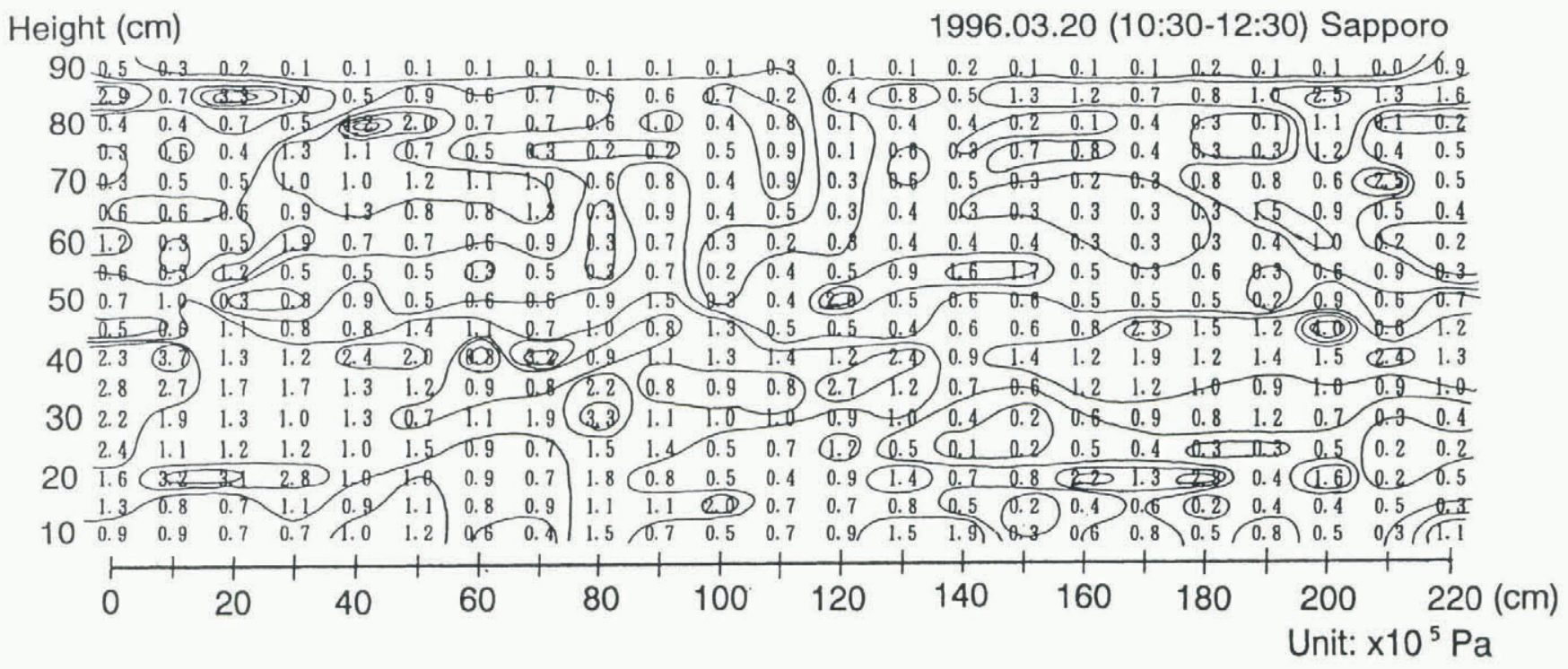

Fig. 8. The spatial distribution of snow hardness at Sapporo in the melt season, 20 March 1996.

1996 are shown in Figure 6. Before early January, the snow depth increased gradually. In the middle of January, there was little snowfall and the air temperature was elevated for several days, so that the snow depth decreased from about $200 \mathrm{~cm}$ to approximately $150 \mathrm{~cm}$. It can be guessed that the granular-snow layer below a height of about $110 \mathrm{~cm}$ in Figure 5 was formed during these days. After that, there was considerable snowfall and low sub-zero air temperatures from the end of January until early February. During these days, the upper compacted snow layer must have been formed. It can therefore be suggested that the hardness distribution of the unmelted snow is horizontally uniform but changes to a heterogeneous state once meltwater infiltrates into the snow layer.

\section{Snow-hardness distribution in the melt season}

The results of snow-pit observations carried out at Sapporo are shown in Figures 7 and 8. The snow depth was $90 \mathrm{~cm}$ and the snow temperature was $0^{\circ} \mathrm{C}$ throughout the snowpack. Granular snow with densities of $400-500 \mathrm{~kg} \mathrm{~m}^{-3}$ could be observed almost throughout the snowpack (Fig. 7). The width of the pit wall where the hardness distribution was measured was $220 \mathrm{~cm}$ (Fig. 8). Hardnesses were smallest near the surface and some hard points could be observed around a height of 20 or $40 \mathrm{~cm}$ but the contour lines are not parallel to each other. It became clear that snow hardness was not horizontally uniform in the melt season. The changes in the hardness distribution can be due to the heterogeneous infiltration of meltwater. Quantitative observations on the heterogeneous infiltration of meltwater have been made by Marsh and Woo (1984, 1985), and Nomura (1994) has described the mechanism of concentrated infiltration.

\section{CONGLUSIONS}

The push-pull gauge can measure snow hardness at small intervals, so it is very good for detecting weak layers which may cause avalanches. Moreover, because it is small and the method of measurement is very easy, it is particularly useful for field observations. Because many measurements can be made quickly, snow-hardness distribution can be achieved at small intervals. From the field data, it became clear that snow hardness was horizontally uniform in dry compacted snow layers and that it tended to increase with depth. The hardness of the fine-grained compacted snow layers with grain-sizes less than $0.5 \mathrm{~mm}$ was proportional to the fourth power of the density and the correlation coefficient was very high. On the other hand, in wet granular-snow layers, the hardness distribution was heterogeneous. This could be due to the heterogeneous infiltration of meltwater. Both snowhardness and snow-density distribution are probably horizontally heterogeneous during the melt season. When a snow-pit observation is made, it should be recognized that the physical property of snow pack changes to heterogeneous during the melt season.

\section{ACKNOWLEDGEMENTS}

The authors are grateful to the following individuals for their support of this study: continuous meteorological data at Saiho were provided by N. Miyazaki of Climate Engineering; field assistance at Saiho was provided by M. Shimizu of the Nagaoka Institute of Snow and Ice Studies and K. Fukami of the Geological Survey of Hokkaido; field assistance at Sapporo was provided by K. Nishimura of Hokkaido University, and at Minakami by Y. Yamada, T. Kobayashi and H. Kanda of Nagaoka Institute of Snow and Ice Studies; T. Yamada of Niigata University also contributed to this study.

\section{REFERENCES}

Colbeck, S. C. and 7 others, 1990. The international classification for seasonal snow on the ground. Wallingford, Oxon, International Association of Scientific Hydrology. International Commission on Snow and Ice.

Kinosita, S. 1960. [The hardness of snow. 1.] Low Temp. Sci., Ser. A 19, 119-134. [InJapanese with English summary.]

Marsh, P. and M.-K. Woo. 1984. Wetting front advance and freezing of meltwater within a snow cover. 1. Observations in the Canadian Arctic. Water Resour. Res., 20 (12), 1853-1864.

Marsh, P. and M. -K. Woo. 1985. Meltwater movement in natural heterogeneous snow covers. Water Resour. Res., 21 (11), 1710-1716.

Nomura, M. 1994. Studies on the delay mechanism of runoff to snowmelt. Contrib. Inst. Low Temp. Sci., Ser. A 39. 